\title{
Characterization of Colletotrichum isolates causing avocado anthracnose and first report of $C$. gigasporum infecting avocado in Sri Lanka
}

\section{Hunupolagama DM ${ }^{1^{*}}$, Wijesundera RLC ${ }^{1}$, Chandrasekharan $\mathrm{NV}^{2}$, Wijesundera WSS $^{3}$, Kathriarachchi HS ${ }^{1}$, Fernando THPS ${ }^{4}$}

\author{
${ }^{1}$ Department of Plant Sciences, University of Colombo, Colombo 03, Sri Lanka. dmhunupolagama@pts.cmb.ac.lk \\ ${ }^{2}$ Department of Chemistry, University of Colombo, Colombo 03, Sri Lanka \\ ${ }^{3}$ Department of Biochemistry and Molecular Biology, Faculty of Medicine, University of Colombo, Colombo 08, Sri \\ Lanka \\ ${ }^{4}$ Rubber Research Institute of Sri Lanka, Dartonfield, Agalawaththa, Sri Lanka.
}

Hunupolagama DM, Wijesundera RLC, Chandrasekharan NV, Wijesundera WSS, Kathriarachchi HS, Fernando THPS 2015 - Characterization of Colletotrichum isolates causing avocado anthracnose and first report of C. gigasporum infecting avocado in Sri Lanka. Plant Pathology \& Quarantine 5(2), 132-143, Doi 10.5943/ppq/5/2/10

\begin{abstract}
Colletotrichum can be identified as the major causative fungal agent of avocado anthracnose all over the world. In Sri Lanka, Colletotrichum gloeosporioides reported to be the sole causative agent of avocado anthracnose. This paper presents a morphological, genetic and pathogenic study conducted using Colletotrichum isolates collected from different avocado cultivating areas of Sri Lanka. Here, the identity of $C$. gloeosporioides has been confirmed using multi locus phylogeny as the major causative agent and provides Colletotrichum gigasporum as a causative agent of avocado anthracnose for the first time in Sri Lanka. Difference of these two species also confirmed by banding patterns obtained using Inter Sequence Simple Repeat (ISSR) primers.
\end{abstract}

Key words - ISSR primed PCR - Morphology - Species specific primers.

\section{Introduction}

Anthracnose is a common disease of tropical fruits, vegetables and leafy vegetables (Cannon et al. 2012). This disease occurs in both developing and mature plant tissues (Binyamini \& Schiffmann 1972), starting as water soaked lesions which rapidly turns black, finally resulting in tissue rot. Colletotrichum sp. is the major causative agent of anthracnose and apart from fruits; the disease also affects other parts of the plants such as leaves, flowers, stem and roots (Sutton 1992, Abang et al. 2009).

Avocado (Persia americana L.) is a popular fruit with a high nutritional value. Anthracnose is a common and an important disease of avocado in Sri Lanka and it causes significant economic losses by reducing shelf life of the fresh produce. Presence of black lesions with the orange conidial masses can have an impact on the consumer preference. The causative agent of avocado anthracnose in Sri Lanka has been reported as Colletotrichum gloeosporioides Penz. \& Sacc. 
(Karunarathne et al. 1999) in the earlier studies conducted. However, there are records from other countries about the involvement of both Colletotrichum gloeosporioides Penz. \& Sacc. and Colletotrichum acutatum Simmonds in avocado anthracnose (Hartill 1991, Peres et al. 2002, Everett 2003, Giblin et al. 2010).

In differentiation of the Colletotrichum species, morphological methods show less advantage because of their variability with the repeated sub-culturing, environmental conditions and nature of the host (Cai et al. 2009). It provides meaningful support when using with the molecular data. Application of species specific primers (White et al. 1990, Sreenivasaprasad et al. 1996), DNA fingerprints obtained using inter sequence simple repeats (ISSR) (Weining \& Langridge 1991, Stenlid et al. 1994) that enable easy identification of pathogens with the help of presence or absence of specific bands and banding patterns and multi locus approach of phylogenetic analysis (Weir et al. 2012, Damm et al. 2012) are some widely applying techniques in Colletotrichum studies. This research has been conducted using such molecular methods along with the morphological methods to investigate and characterize the Colletotrichum sp. causing avocado anthracnose in Sri Lanka.

\section{Materials \& Methods}

\section{Sample collection and isolation of the pathogen}

Infected fruits and twigs of avocado were collected from avocado cultivated localities in Kandy, Nuwara Eliya, Colombo and Polonnaruwa districts of Sri Lanka. They were placed on punched poly-propylene bags and transported to the laboratory within 24 hours. The collected samples were incubated in moist chambers at the laboratory to enhance sporulation. Two reference cultures of $C$. gloeosporioides (UOC_PTSCC_CgRef) and $C$. acutatum (UOC_PTSCC_CaRef) from the Colletotrichum culture collection maintained at the Department of Plant Sciences, University of Colombo has been used in this study which were originally obtained from the Rubber Research Institute of Sri Lanka. Identities of these cultures were confirmed by a preliminary study conducted with gene sequences of other members of $C$. acutatum and $C$. gloeosporioides species complexes.

The infected areas were separated with the surrounding healthy tissues and surface sterilized with $70 \%$ ethanol for 30 seconds. Then the samples were blot dried using sterilized tissue papers. After that the lesions were aseptically cut opened and transferred to Potato Dextrose Agar (PDA) plates. After 4 days of incubation at $25{ }^{0} \mathrm{C}$, mycelia which emerged from the lesions were transferred to fresh PDA plates to obtain pure cultures and single conidia derived cultures (Choi et al. 1999). The single conidia derived cultures of the isolates were used for all further experiments. Seven cultures representing above four districts were used for morphological and genetic characterization.

\section{Morphological characters}

Colors of upper and lower sides, nature of the margins, texture, appearance, shape and presence of concentric rings were recorded using 7- day old cultures on PDA. Five replicates from each sample were used for the experiment.

The growth rate of isolates on PDA was calculated by measuring the daily increment of the culture diameter for ten days. The cultures were prepared by placing a $7 \mathrm{~mm}$ diameter mycelium disc obtained from a 7-day old culture of the isolate on a fresh PDA plate. Two diameter readings perpendicular to each other were taken at a time using five replicate cultures of each isolate.

To determine the growth on liquid medium, the fungus was grown in $50 \mathrm{ml}$ of Malt Extract broth in $250 \mathrm{ml}$ Erlenmeyer flasks. Each broth was inoculated with a $7 \mathrm{~mm}$ diameter mycelium disc obtained from a 7-day old culture of the fungus on PDA and incubated without shaking at $25^{\circ} \mathrm{C}$ for 15 days. The mycelium was harvested at three day intervals by filtering through Whatman No.1 filter paper. The harvested mycelium was oven dried at $80^{\circ} \mathrm{C}$ for $24 \mathrm{~h}$ and the weight was measured. The rate of 
increase in dry weight was taken as the rate of the growth. At each point three flasks were harvested.

Slide cultures of the isolates on PDA were used to determine the color, shape and the dimensions of the conidia and appressoria. Randomly selected 100 conidia and 100 appressoria were used and the experiment was triplicated (Sutton 1980, Du et al. 2005).

Conidia concentration in 7-day old PDA cultures was measured by counting the number of conidia in a distilled water suspension with the use of a counting chamber. To prepare the conidia suspension, $10 \mathrm{ml}$ of distilled water was added to a 7-day old culture, gently shaken to suspend the conidia in water and filtered through a muslin cloth to remove the mycelia. To measure the concentration of conidia in broth cultures, 7-day old broth culture prepared as described above was used. At the end of the seven day period, flasks were gently shaken and filtered through a muslin cloth. The resulting filtrate was used to count the number of conidia using the counting chamber. Conidial concentration was calculated as the number of conidia produced per square centimeter of a seven-day old culture. Shape, color and distribution of conidial masses were also observed in the 7 - day old culture on PDA using a stereo microscope (Luxeo 2S).

\section{Genetic characters}

DNA was extracted from mycelia scraped from two-day old cultures on PDA (Hunupolagama et al. 2014) and quantified using a UV spectrophotometer. Here Two - day old cultures prepared as spread plates were used to avoid different color compounds developing in cultures with the maturity, which may affect to the purity of the final DNA sample.

All isolates were subjected to polymerase chain reaction (PCR) using ITS4 universal primer together with species specific primers, CaInt 2 for $C$. acutatum and $\mathrm{CgInt}$ for $C$. gloeosporioides (Sreenivasaprasad et al. 1996). Total volume of the PCR reaction mixture was $25 \mu 1$ which included $1 \mu 1$ of 20 fold diluted genomic DNA; $50 \mathrm{mM} \mathrm{KCL;} 10 \mathrm{mM}$ Tris- $\mathrm{HCl} ; 0.2 \mathrm{mM}$ each dATP, dTTP, dGTP, dCTP; $1.5 \mathrm{mM} \mathrm{MgCl} 2$; 2 units of Taq DNA Polymerase ( UCBiotech, Sri Lanka), and 0.2 $\mu \mathrm{M}$ ITS4 primer and $0.2 \mu \mathrm{M}$ CaInt 2 or CgInt primers. Genomic DNA of the reference cultures was added as the templates for the positive control and negative control. All the reactions were triplicated in a thermo cycler (Ependorf master cycler- USA) starting with 5 min of denaturation at $95^{\circ} \mathrm{C}$ followed by 35 cycles of $30 \mathrm{~S}$ at $95^{\circ} \mathrm{C}, 30 \mathrm{~S}$ at $60^{\circ} \mathrm{C}$ and $90 \mathrm{~S}$ at $72^{\circ} \mathrm{C}$ (McKay et al. 2009) and 5 min of final extension at $72^{\circ} \mathrm{C}$. Amplified DNA products were separated using $1 \%(\mathrm{wt} / \mathrm{vol})$ agarose gel incorporated with ethidium bromide $(0.5 \mu \mathrm{g} / \mathrm{ml})$ in $1 \mathrm{X}$ Tris-acetate EDTA buffer ( 40 $\mathrm{mM}$ Tris acetate, $1 \mathrm{mM}$ EDTA, $\mathrm{P}^{\mathrm{H}} 8.3$ ) by electrophoresis at $100 \mathrm{v}$ for $15 \mathrm{~min}$. Observations were taken with the use of a gel documentation system.

Four nuclear gene regions including Internal transcribed spacer region (ITS), actin (ACT), glyceraldehyde-3-phosphate dehydrogenase (GAPDH) and $\beta$-tubulin 2 (TUB2) were amplified using primer pairs, ITS1EXT and ITS4EXT (Talhinhas et al. 2002), ACT-512F and ACT783R(Carbone \& Kohn 1999), GDF and GDR(Templeton et al. 1992), T1(O’Donnell \& Cigelnik 1997) and Bt2b (Glass \& Donaldson 1995) respectively. Reaction volume, PCR protocol and concentrations of each reagent for ITS region was same as described in species specific primed PCR. For other three gene regions, concentration of the PCR buffer, genomic DNA and Taq DNA Polymerase was same as above with $2 \mathrm{mM} \mathrm{MgCl}_{2}$ and $1.5 \mu \mathrm{LMSO}$. PCR protocol for those three gene regions was started with 5 mins initial denaturation at $94^{\circ} \mathrm{C}$ followed by 35 cycles of 30 s at $95^{\circ} \mathrm{C}, 30 \mathrm{~s}$ at $60^{\circ} \mathrm{C}$ for GAPDH, $55^{\circ} \mathrm{C}$ for TUB2 and $58^{\circ} \mathrm{C}$ for ACT and $45 \mathrm{~s}$ at $72^{\circ} \mathrm{C}$. Final extension was 7 mins at $72^{\circ} \mathrm{C}$. Resulted PCR products were sequenced and the sequences were deposited in GenBank.

Three ISSR primers, $(\mathrm{CAG})_{5},(\mathrm{GTG})_{5}$ and $(\mathrm{CAC})_{5}$ were used (McKay et al. 2009) to amplify the genomic DNA of avocado isolates. Reaction mixture and PCR conditions were same as described in species specific primers, except the primer concentration $(0.4 \mu \mathrm{M})$. Amplified products were separated and observed using $2 \%(\mathrm{wt} / \mathrm{vol}$ ) agarose gel at $70 \mathrm{v}$ in $0.5 \mathrm{X}$ Tris-borate EDTA buffer (40mM Tris borate, 1mM EDTA, pH 8.3). 


\section{Pathogenic characters}

$10 \mathrm{ml}$ of sterilized distilled water was added to 14 days old well sporulated pure cultures of C. gloeosporioides and C. gigasporum and gently swirreled to mix well. Resulted conidial and mycelial suspension was filtered through two layers of sterilized muslin cloth and the concentration of conidia was adjusted to $1 \times 10^{6} / \mathrm{ml}$ using a heamocytometer (Tshering 2006).

Matured, unripe detached avocado fruits were first washed with running tap water for $1 \mathrm{~min}$ and wiped with $70 \%$ ethanol. Then they were washed three times with sterilized distilled water and dried with sterile tissue papers (Sanders \& Korsten 2003). Surface sterilized fruits were inoculated according to wound/drop method (Lin et al. 2002). Middle of the fruits was pin-pricked using sterile needle and $6 \mu 1$ of conidial suspension was placed on the wound (Freeman \& Shabi, 1996). Inoculated fruits and controls were incubated in moisture chambers for 10 days at $25{ }^{0} \mathrm{C}$. Relative humidity was maintained around $95 \%$, placing sterilized cotton ball soaked in sterilized distilled water (Than et al. 2008).

\section{Data analysis}

Based on morphological characters, Colletotrichum isolates obtained from avocado samples were subjected to multivariate analysis followed by a principal component analysis, using SPSS 16.0. A dendrogram was developed using average linkage according to the Euclidian root method. ITS, GAPDH, ACT and TUB2 sequences obtained from all avocado isolates, reference isolates and reference sequences downloaded from Genbank was aligned using Muscle (Edgar \& Robert 2004). The evolutionary history was inferred by using the Maximum Likelihood method based on the Kimura 2-parameter model (Kimura 1980). The tree with the highest log likelihood (-2158.6612) is shown. The percentage of trees in which the associated taxa clustered together is shown next to the branches. Initial tree(s) for the heuristic search was obtained automatically by applying NeighborJoin and BioNJ algorithms to a matrix of pair wise distances estimated using the Maximum Composite Likelihood (MCL) approach, and then selecting the topology with superior log likelihood value. A discrete Gamma distribution was used to model evolutionary rate differences among sites $(5$ categories $(+\mathrm{G}$, parameter $=0.3006))$. The tree is drawn to scale, with branch lengths measured in the number of substitutions per site. The analysis involved 26 nucleotide sequences. All positions containing gaps and missing data were eliminated. There were a total of 674 informative positions in the final dataset. Evolutionary analyses were conducted in MEGA6 (Tamura et al. 2013)

\section{Results}

\section{Morphological characters}

Arial mycelium of the $C$. gigasporum culture (UOC_PTSCC_AVC1) was grey in middle with white outer region and occurred as tufts in some times (Fig. 1). Revers side of the culture had greenish grey middle region with dark green patches arranged as concentric rings and off-white outer region (Fig. 2). Pale orange and grey conidial masses were scattered throughout the culture (Fig. 3). Large amount of acervuli were present. Conidiogenous cells were hyaline, cylindrical to clavate. Smooth walled, hyaline, cylindrical conidia (Fig. 4) (Table 1) and brown, dark walled appressoria (Fig. 5) (Table 1), variable in shape and sizes were observed in slide culture.

Arial mycelium of all C. gloeosporioides cultures were greyish white and cottony (Fig. 6). Reverse side of the cultures were vary in color from off-white to light greenish grey with orange centre (Fig. 7). Orange, sessile conidial masses were observed mainly on the centre of the culture (Fig. 8). Conidiogenous cells were clavate or cylindrical (Fig. 9). Conidia were hyaline, cylindric to clavate with rounded ends or slightly tapering from one end (Fig. 10) (Table 1). Grey to light brown, dark walled appressoria (Fig. 11) were clavate, oval or irregular shaped and variable in size (Table 1). 

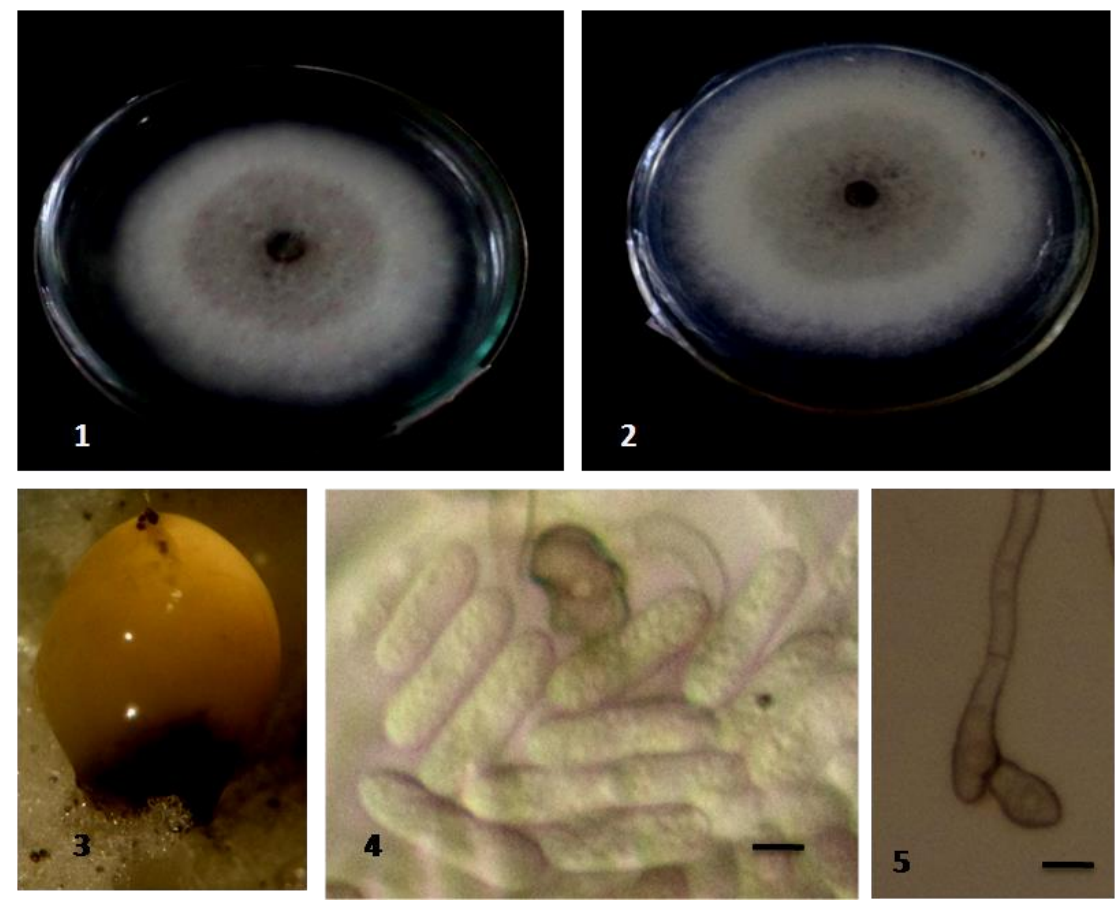

Figs 1 - 5-Colletotrichum gigasporum isolate UOC_PTSCC_AVC1. 1, Upper side of the sevenday old culture on PDA. 2, Reverse side of the seven-day old culture on PDA. 3, Conidial mass. 4, Mature conidia $($ Scale bar $=5 \mu \mathrm{m}) .5$, Appressorium $($ Scale bar $=8 \mu \mathrm{m})$.
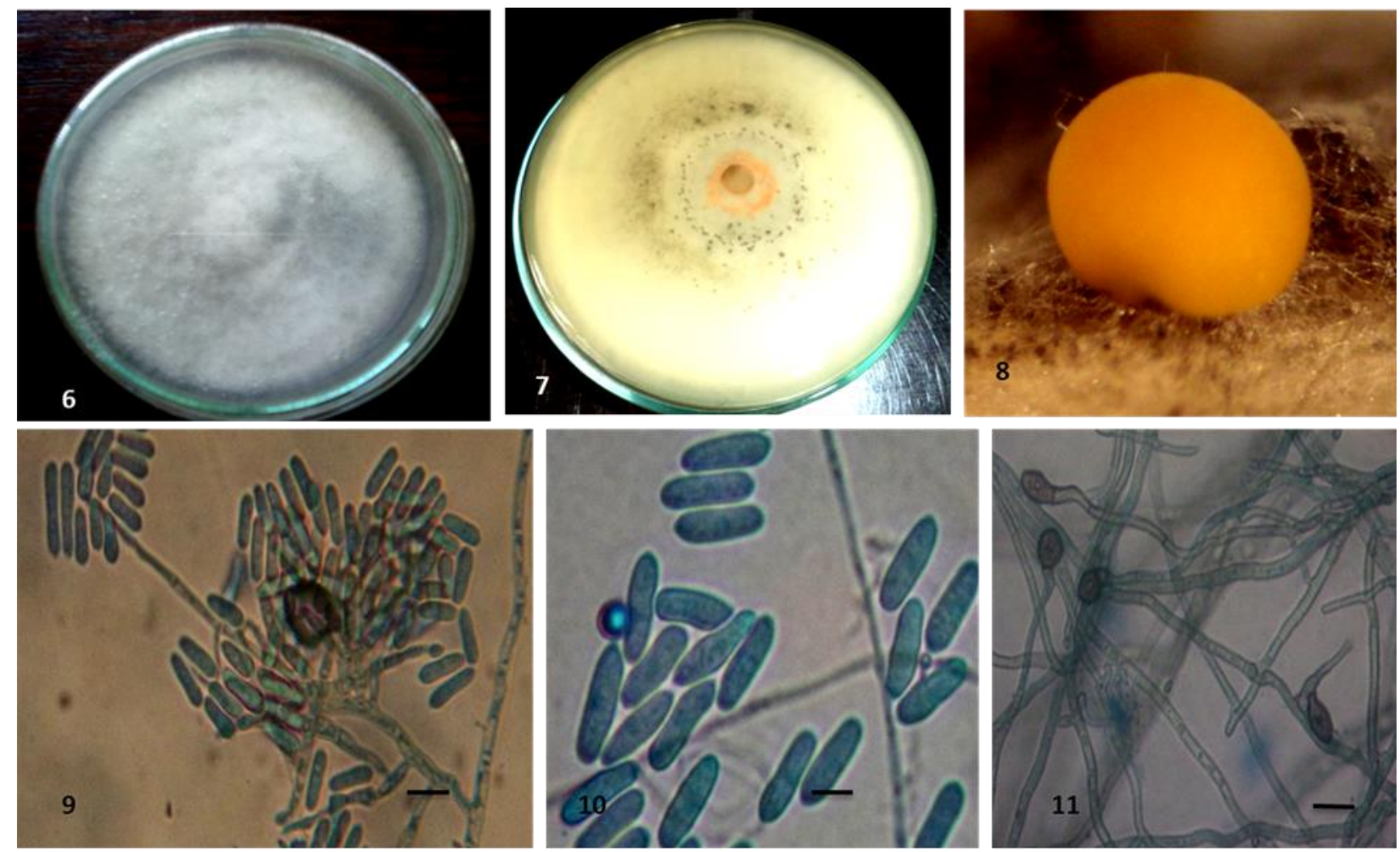

Figs 6 - 11 - Colletotrichum gloeosporioides isolate UOC_PTSCC_AVN2. 6, Upper side of the seven-day old culture on PDA. 7, Reverse side of the seven-day old culture on PDA. 8, Conidial mass. 9, Conidiophore naring conidia and conidiogenous cells. 10, Mature conidia. 11, Appressoria. - Scale bars $=10 \mu \mathrm{m}$. Conidia, Appressoria and conidiophore were stained using Cotton blue reagent. 
Table 1 Morphological characters of different isolates of Colletotrichum isolated from diseased avocado samples.

\begin{tabular}{|c|c|c|c|c|c|c|c|}
\hline \multirow{2}{*}{ Isolate } & \multirow[t]{2}{*}{ Name } & \multicolumn{2}{|c|}{ Conidia } & \multicolumn{2}{|c|}{ Appresoria } & \multicolumn{2}{|c|}{ Growth rate } \\
\hline & & $\begin{array}{l}\text { Mean } \\
\text { length } \\
(\mu \mathrm{m})\end{array}$ & $\begin{array}{l}\text { Mean } \\
\text { width } \\
(\mu \mathrm{m})\end{array}$ & $\begin{array}{l}\text { Mean } \\
\text { length } \\
(\mu \mathrm{m})\end{array}$ & $\begin{array}{l}\text { Mean } \\
\text { width } \\
(\mu \mathrm{m})\end{array}$ & $\begin{array}{l}\text { Radial } \\
\text { growth } \\
\text { rate } \\
\text { (mm } \\
\text { /day) }\end{array}$ & $\begin{array}{l}\text { Rate of } \\
\text { increase } \\
\text { of dry } \\
\text { weight } \\
\text { (g/day) }\end{array}$ \\
\hline UOC_PTSCC_AVC1 & C. gigasporum & $\begin{array}{l}18- \\
22.50- \\
30\end{array}$ & $\begin{array}{l}7- \\
8.00- \\
10\end{array}$ & 18.75 & 8.00 & 12.70 & 0.02 \\
\hline $\begin{array}{l}\text { UOC_PTSCC_AVN2, } \\
\text { UOC_PTSCC_AVK3, } \\
\text { UOC_PTSCC_AVH4, } \\
\text { UOC_PTSCC_AVH5, } \\
\text { UOC_PTSCC_AVN6, } \\
\text { UOC_PTSCC_AVP7, }\end{array}$ & C.gloeosporioides & $\begin{array}{l}15- \\
18.50- \\
20\end{array}$ & $\begin{array}{l}5- \\
7.00- \\
7.5\end{array}$ & 16.00 & 7.50 & 09.50 & 0.02 \\
\hline
\end{tabular}

\section{Genetic characters}

All avocado isolates and C. gloeosporioides reference isolate (UOC_PTSCC_CgRef) produced $450 \mathrm{bp}$ fragments for PCR performed with species specific primer CgInt and ITS4 universal primer. Only the C. acutatum reference isolate (UOC_PTSCC_CaRef) gave 490bp band with species specific primer CaInt and ITS4 universal primer (Fig. 12).

All three ISSR primers produced polymorphic banding patterns upon the PCR amplification with the seven isolates. Fig. 13 shows the banding patterns produced by (CAC) 3 , (CAG) 5 and (GTG) 5 . Among three primers, (CAG) 5 produced eight to twelve PCR fragments and three different patterns were observed among the isolates. (GTG) 5 produced seven to ten PCR fragments and two different patterns were observed. (CAC) 3 unlike the (CAG) 5 and (GTG) 5, produced two prominent PCR fragments of 1000bp and 750bp while giving an equal pattern among all isolates. All together there were 19 polymorphic PCR fragments. Each primer produced 2- 10 prominent PCR fragments with each isolate.

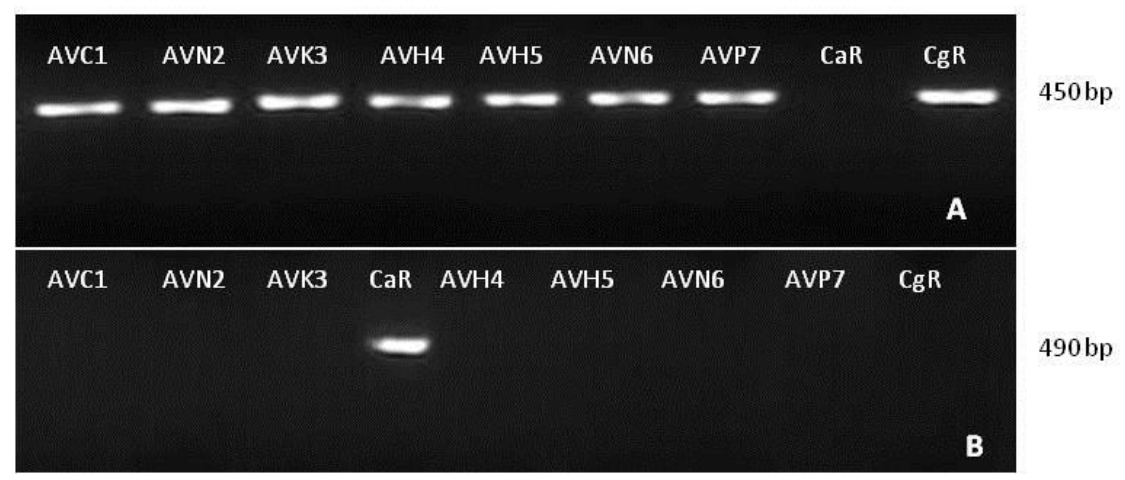

Fig 12 - A, PCR amplified products of seven test isolates and two reference-isolates using $C$. gloeosporioides specific primer CgInt. B, PCR amplified products of seven test isolates and two reference-isolates using $C$. acutatum specific primer $\mathrm{CaInt}$. $\mathrm{CaR}-C$. acutatum reference culture (UOC_PTSCC_CaRef) CgR - C. gloeosporioides reference culture (UOC_PTSCC_CgRef). 
Table 2 GenBank accession numbers of the sequences used in this study. Sequences generated in this study are shown in bold.

\begin{tabular}{|c|c|c|c|c|c|}
\hline \multirow[t]{2}{*}{ Isolate } & \multirow{2}{*}{$\begin{array}{l}\text { Culture } \\
\text { collection } \\
\text { accession } \\
\text { number }\end{array}$} & \multicolumn{4}{|c|}{ GenBank accession number } \\
\hline & & ITS & GAPDH & ACT & TUB2 \\
\hline \multirow[t]{12}{*}{ C. gloeosporioides } & $\begin{array}{l}\text { UOC_PTSCC_A } \\
\text { VN2 }\end{array}$ & KT007117 & KT228302 & KT228311 & KT200519 \\
\hline & $\begin{array}{l}\text { UOC_PTSCC_A } \\
\text { VK3 }\end{array}$ & KT007118 & KT228303 & KT228312 & KT200511 \\
\hline & $\begin{array}{l}\text { UOC_PTSCC_A } \\
\text { VH4 }\end{array}$ & KT007119 & KT228304 & KT228313 & KT200512 \\
\hline & $\begin{array}{l}\text { UOC_PTSCC_A } \\
\text { VH5 }\end{array}$ & KT007120 & KT228305 & KT228314 & KT200513 \\
\hline & $\begin{array}{l}\text { UOC_PTSCC_A } \\
\text { VN6 }\end{array}$ & KT007121 & KT228306 & KT228315 & KT200514 \\
\hline & $\begin{array}{l}\text { UOC_PTSCC_A } \\
\text { VP7 }\end{array}$ & KT007122 & KT228307 & KT228316 & KT200515 \\
\hline & $\begin{array}{l}\text { UOC_PTSCC_Cg } \\
\text { Ref }\end{array}$ & KT007124 & KT228309 & KT228318 & KT200517 \\
\hline & IMI 356878 & JX010152 & JX010056 & JX009531 & JX010445 \\
\hline & ICMP12939 & JX010149 & JX009931 & JX009462 & \\
\hline & ICMP12066 & JX010158 & JX009955 & JX009550 & \\
\hline & ICMP12938 & JX010147 & JX009935 & JX009560 & \\
\hline & ICMP18695 & JX010153 & JX009979 & JX009494 & \\
\hline \multirow[t]{2}{*}{ C. acutatum } & $\begin{array}{l}\text { UOC_PTSCC_Ca } \\
\text { Ref }\end{array}$ & KT007123 & KT228308 & KT228317 & KT200516 \\
\hline & CBS 112996 & JQ005776 & JQ948677 & JQ005839 & JQ005860 \\
\hline \multirow[t]{5}{*}{ C. gigasporum } & CBS101881 & KF687736 & KF687841 & KF687797 & KF687886 \\
\hline & CBS109355 & KF687729 & KF687827 & KF687798 & KF687870 \\
\hline & CBS124947 & KF687731 & KF687828 & KF687786 & KF687871 \\
\hline & CBS125385 & KF687732 & KF687835 & KF687787 & KF687872 \\
\hline & $\begin{array}{l}\text { UOC_PTSCC } \\
\text { AVC1 }\end{array}$ & KT007116 & KT228301 & KT228310 & KT200518 \\
\hline \multirow[t]{2}{*}{ C. arxii } & CBS132511 & KF687716 & KF687824 & KF687784 & KF687768 \\
\hline & IMI304050 & KF687717 & KF687843 & KF687802 & KF687881 \\
\hline C. magnisporum & CBS398.84 & KF687718 & KF687842 & KF687803 & KF687882 \\
\hline C.pseudomajus & CBS571.88 & KF687722 & KF687826 & KF687801 & KF687883 \\
\hline C. radicis & CBS529.93 & KF687719 & KF687825 & KF687785 & KF687869 \\
\hline \multirow[t]{2}{*}{ C. vietnamense } & CBS 125477 & KF687720 & KF687831 & KF687791 & KF687876 \\
\hline & CBS125478 & KF687721 & KF687832 & KF687792 & KF687877 \\
\hline
\end{tabular}

The combined data set of ITS, GAPDH, ACT and TUB2 sequences consisted 1806 characters and out of them 674 characters were used for analysis. Maximum parsimony and maximum likelihood produced identical tree topologies. Colletotrichum gloeosporioides isolates obtained from diseased avocado samples were clustered together with $C$. gloeosporioides reference isolates with $100 \%$ bootstrap value. Colletotrichum gigasporum isolate obtained in this study also 
clustered with $C$. gigasporum reference isolates forming a well supported clade with $100 \%$ bootstrap support. That confirms the identity of both species (Fig. 16).

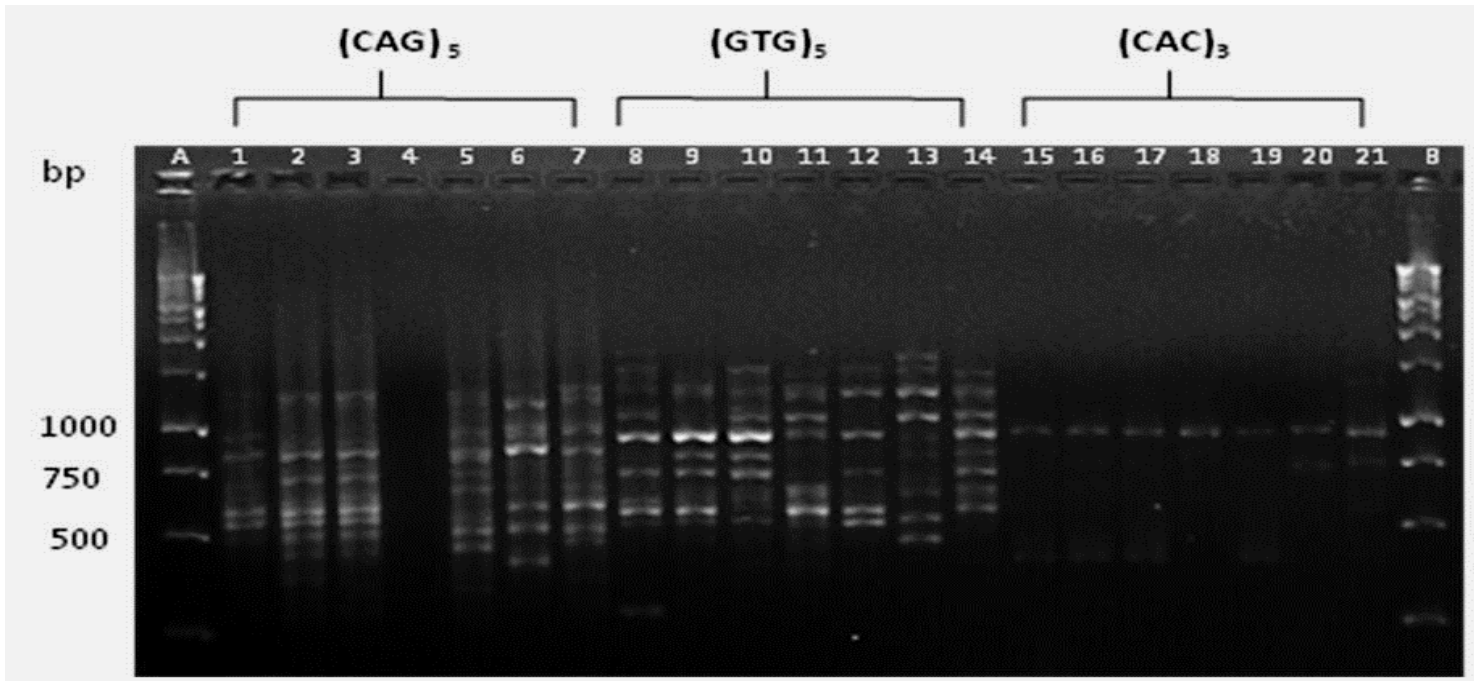

Fig 13 - DNA banding patterns obtained for PCR reactions with the inter simple sequence repeat (ISSR) primers $(\mathrm{CAG})_{5},(\mathrm{GTG})_{5}$ and $(\mathrm{CAC})_{3}$. Lane A and B, 1kb ladder; lanes 1-7, 8-14 and 1521: amplification products of AVC1, AVN2, AVK3, AVH4, AVH5, AVN6 and AVP7, obtained with the primers $(\mathrm{CAG})_{5},(\mathrm{GTG})_{5}$ and $(\mathrm{CAC})_{3}$ respectively

\section{Pathogenic characters}

Fulfilling the Koch's postulates, fruits inoculated with $C$. gigasporum started to show disease symptoms after two days after inoculation and at the $10^{\text {th }}$ day typical anthracnose lesions were observed with fruit discoloration (Fig. 14). Fruits inoculated with C. gloeosporioides started to show disease symptoms after four days and at the $10^{\text {th }}$ day they also exhibited anthracnose symptoms little lower than the $C$. gigasporum.

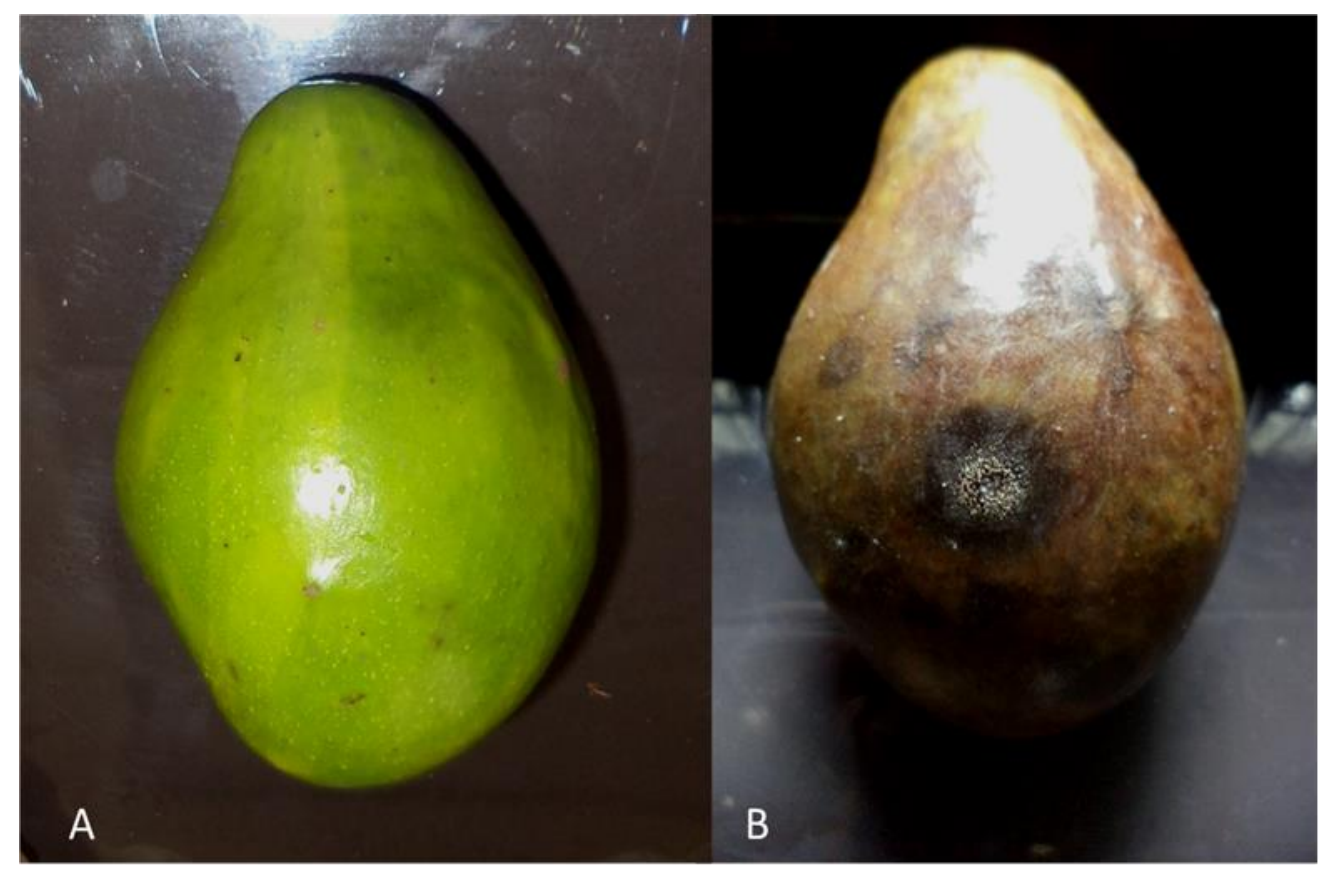

Fig 14 - Avocado fruits exhibiting typical anthracnose symptoms up on the inoculation of C. gigasporum conidia suspension. A, Control. B, Infected fruit after 10 days. 


\section{Discussion}

All isolates except UOC_PTSCC_AVC1 resembled the characters of $C$. gloeosporioides in their morphological characters (Weir et al. 2012) and growth with slight variations in conidial and appressorial characters among each other. This agrees with the observations reported by Damm et al. (2012) that there are many intermediate strains of both $C$. acutatum and $C$. gloeosporioides showing different conidial and appressorial characters. Characters of UOC_PTSCC_AVC1, which identified as $C$. gigasporum, were similar to the characters recorded by Noireung et al. (2012) and Liu et al. (2014). However according to the results of morphological study all isolates were belonged in to three morphologically different groups (Fig. 15). That may be due to the principle components like conidia shape and appressoria shape which used to develop the dendrogram.

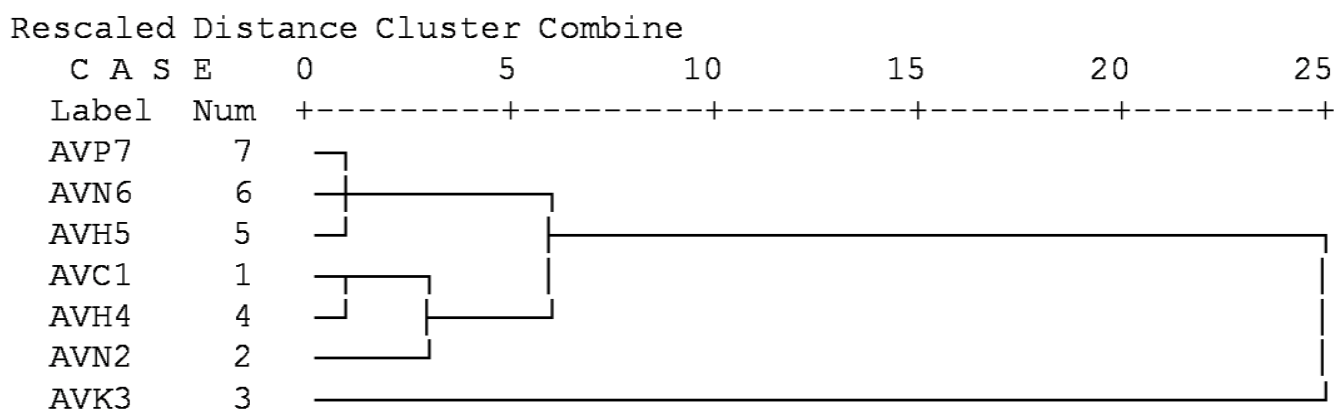

Fig 15 - Dendrogram developed according to the Euclidian method for morphological characters of seven Colletotrichum isolates from Avocado using SPSS 16.0

Complying with the results of Freeman and Katan (2007) all avocado isolates and C. gloeosporioides reference isolate (UOC_PTSCC_CgRef) produced 450bp fragments for PCR performed with species specific primer CgInt and ITS4 universal primer (Fig. 12 - A). Only the C. acutatum reference isolate (UOC_PTSCC_CaRef) produced 490bp band with species specific primer CaInt and ITS4 universal primer (Fig. 12 - B). However, C. gigasporum that belongs to C. gigasporum species complex also provided positive results for $C$. gloeosporioides species specific primers. With that result it can be concluded the species specific primers for C. gloeosporioides used in this study can no longer be used to separate $C$. gloeosporioides from the other species. Hence studying applicability of these species specific primers with larger data sets can be recommended.

In ISSR primed PCR analysis, number of fragments resulted was complies with the results obtained by McKay et al. (2009) and the patterns were slightly different from that research. However, there was reasonable number of fragments of same weight that match with results of the present study. Therefore, this method may be further improved to generating reference banding patterns for different species of Colletotrichum and can be used when required quick identification. The overall result of this investigation establish the fact that $C$. gloeosporioides is not the only causal agent of Avocado anthracnose in Sri Lanka. However, higher percentage of the isolates examined was $C$. gloeosporioides. Like in several other countries, there can be more different Colletotrichum species exist as causal organisms of avocado anthracnose in Sri Lanka. A study with larger number of isolates can be recommended for further investigation of species diversity. 


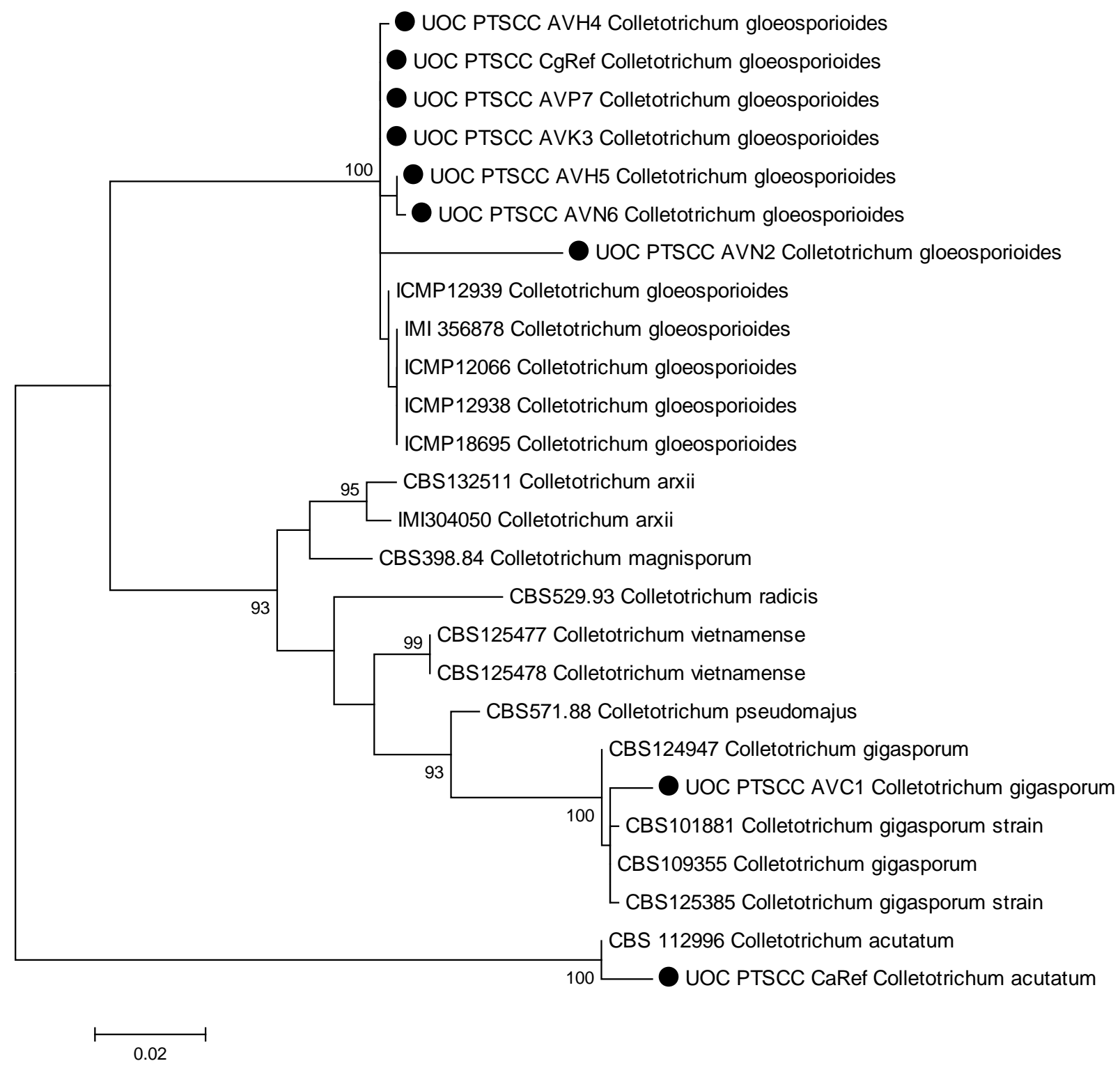

Fig 16 - Maximum likelihood Phylogenetic tree generated using ITS, GAPDH, ACT and TUB2 sequences of Colletotrichum isolates from diseased Avocado samples and sequences downloaded from the GenBank by using MEGA 6. Isolates studied in this study were marked with bullets. The tree is drawn to scale, with branch lengths measured in the number of substitutions per site.

Furthermore to the best of our knowledge this is the first report of $C$. gigasporum as a causal agent of Avocado anthracnose in Sri Lanka or any other country.

\section{Acknowledgements}

Financial assistance for this research was provided by World Bank grant HETC/QIG/W3 of University of Colombo, Sri Lanka. We acknowledge Mrs. R. Maddumage for the provided technical assistance.

\section{References}

Abang MM, Araham W, Asiedu R, Hoffmann P, Wolf G, Winter S. 2009 - Secondary metabolite profile and phyto toxic activity of genetically distinct forms of Colletotrichum gloeosporioides from Yam (Dioscorea spp.). Mycological research 113, 130-140.

Binyamini N, Schiffmann-Nadel M. 1972 - Latent infection in avocado fruit due to Colletotrichum gloeosporioides. Phytopathology 62, 592-594. 
Cai L, Hyde KD, Taylor PWJ, Weir BS, Waller JM, Abang MM, Zhang JZ, Yang, YL, Phoulivong S, Liu ZY, Prihastuti H, Shivas RG, McKenzie EHC, Johnston PR. 2009 - A Polyphasic Approach for Studying Colletotrichum. Fungal Diversity 39, 183-204.

Cannon PF, Damm U, Johnston PR, Weir BS. 2012 - Colletotrichum - Current Status and Future Directions. Studies in mycology 73(1), 181-213.

Carbone I, Kohn LM. 1999 - A method for designing primer sets for speciation studies in filamentous ascomycetes. Mycologia 91, 553-556.

Choi YW, Hyde KD, Ho WH. 1999 - Single spore isolation of fungi. Fungal diversity 3, 29-38.

Damm U, Cannon PF, Wondenberg JHC, Crons PW. 2012 - The Colletotrichum acutatum species complex. Studies in mycology 73, 37-113.

Du MZ, Schardl CL, Vaillancourt LJ. 2005 - Using mating- type gene sequence for improved phylogenetic resolution of Colletotrichum species complexes. Mycologia 97, 641-658.

Edgar, Robert C, 2004 - MUSCLE: multiple sequence alignment with high accuracy and high throughput. Nucleic Acid Research 32(5), 1792-1797.

Everett KR, 2003 - The effect of low temperatures on Colletotrichum acutatum and Colletotrichum gloeosporioides causing body rots of avocado in New Zealand. Plant pathology 32, 441448.

Freeman S, Katan. 2007 - Identification of Colletotrichum species responsible for anthracnose and root necrosis of strawberry in Israel. Phytopathology 87(5), 516-521.

Freeman S, Shabi E. 1996 - Cross infection of subtropical and temperate fruits by Colletotrichum species from various hosts. Physiological and Molecular Plant Pathology 49, 395-404.

Giblin FR, Coates LM, Irwin JAG. 2010 - Pathogenic diversity of avocado and mango isolates of Colletotrichum gloeosporioides causing anthracnose and pepper spot in Australia. Plant pathology 39, 50-62.

Glass NL, Donaldson GC. 1995 - Development of primer sets designed for use with the PCR to amplify conserved genes from filamentous ascomycetes. Applied and Environmental Microbiology 61, 1323-1330.

Hartill WFT. 1991 - Post harvest diseases of avocado fruits in New Zealand. New Zealand journal of crop and horticultural science 19, 297-304.

Hunupolagama DM, Wijesundera RLC, Chandrasekharan NV, Wijesundera WSS, Fernando THPS. 2014 - A high yielding and low cost protocol for extract genomic DNA from Colletotrichum sp. which can effectively use in phylogenetic studies; $10^{\text {th }}$ International Mycological congress, Queen Sirikit International convention center, Bangkok, Thailand.

Karunarathne AM, Thattil RO, Adhikaram NKB. 1999 - Population dynamics of Colletotrichum gloeosporioides on different parts of Avocado (Persea americana) tree. Journal of National Science Foundation of Sri Lanka 27(3), 149-164.

Kimura M. 1980 - A simple method for estimating evolutionary rate of base substitutions through comparative studies of nucleotide sequences. Journal of Molecular Evolution 16, 111-120.

Lin Q, Kanchana-udomkarn C, Jaunet T, Mongkolporn O. 2002 - Genetic analysis of resistance to pepper anthracnose caused by Colletotrichum capsici. Thai journal of Agricultural science 35, 259-264.

Liu F, Cai L, Crous PW, Damm U. 2014 - The Colletotrichum gigasporum species complex. Persoonia 33, 83-97.

McKay SF, Freeman S, Minz D, Maymon M, Sedgley M, Collins GC, Scott ES. 2009 Morphological genetic and pathogenic characterization of Colletotrichum acutatum, the cause of anthracnose of Almond in Australia. Phytopathology 99(8), 985-995.

Noireung P, Phoulivong S, Liu F, Cai L, McKenzie EHC, Chukeatirote E, Jones EBG, Bahkali AH , hyde KD. 2012 - Novel species of Colletotrichum revealed by morphology and molecular analysis. Cryptogamie Mycologie 33(3), 1-17.

O’Donnell K, Cigelnik E. 1997 - Two divergent intragenomic rDNA ITS2 types within a monophyletic lineage of the fungus Fusarium are nonorthologous. MoIecular Phylogenetics and Evolution 7, 103-116. 
Peres NAR, Kuramae EE, Dias MSC, Ee Souza NL. 2002 - Identification and characterization of Colletotrichum spp. affecting fruits after harvesting in Brazil. Phytopathology 150, 128134.

Sanders GM, Korsten L. 2003 - Comparison of cross inoculation potential of South African avocado and mango isolates of Colletotrichum gloeosporioides. Microbiological Research 128, 143-150.

Sreenivasaprasad S, Sharada K, Brown AE, Mills PC. 1996 - PCR-based detection of Colletotrichum acutatum on strawberry. Plant pathology 45, 650-655.

Stenlid J, Karlson J, Hogberg N. 1994 - Intraspecific genetic variation in Heterobasidion annosum revealed by amplification of mini satellite DNA. Mycological research 98, 57-63.

Sutton BC. 1980 - The coelomycetes, fungi imperfecti with pycnidia, acervuli and stromata. Common wealth mycological institute, Kew, England.

Sutton BC. 1992 - The genus Glomerella and its anamorph Colletotrichum. In: Bailey JA, Jeger MJ (ed), Colletotrichum biology, pathogenecity and control. CAB International, Wallingford, UK.

Talhinhas P,Sreenivasaprasad S, Neves-Martins J, Oliveira H. 2002 - Genetic and Morphological Characterization of Colletotrichum acutatum Causing Anthracnose of Lupins. Phytopathology 92(9), 986-996.

Tamura K, Stecher G, Peterson D, Filipski A, Kumar S. 2013 - MEGA6: Molecular Evolutionary Genetics Analysis version 6.0. Molecular Biology and Evolution 30, 2725-2729.

Templeton MD, Rikkerink EHA, Solon SL, Crowhurst RN. 1992 - Cloning and molecular characterization of the glyceraldehyde-3-phosphate dehydrogenaseencoding gene and cDNA from the plant pathogenic fungus Glomerella cingulata. Gene 122, 225-230.

Than PP, Jeewon R, Hyde KD, Pongsupasamit S, Mongkolporn O, Taylor PWJ. 2008 Characterization and pathogenicity of Colletotrichum species associated with anthracnose on chili (Capsicum spp.) in Thailand. Plant Pathology 57, 562-572.

Tshering K. 2006 - Host-pathogen interaction of Colletotrichum capsici on chili peppers. M. Sc. Thesis. The University of Melbourne.

Weining S, Langridge P. 1991 - Identification and mapping of polymorphism in cereals based on polymerase chain reaction. Theoretical and applied genetics 82, 209-216.

Weir BS, Johnston PR, Damm U. 2012 - The Colletotrichum gloeosporioides species complex. Studies in mycology 73, 115-180.

White TJ, Bruns T, Lee S, Taylor J. 1990 - Amplification and direct sequencing of fungal ribosomal RNA genes for phylogenetics. In: Innes M, Gelfand D, Sninsky J, White T (ed), PCR protocols: A guide to methods and applications. Academic press, San Diego, pp $230-$ 257. 